\title{
CONTEÚDO TELEVISIVO NA FORMAÇÃO PROFISSIONAL EM EDUCAÇÃO FÍSICA
}

Anderson dos Santos Carvalho ${ }^{1}$, Aline Madia Mantovani ${ }^{2}$, Gustavo Boim de Souza ${ }^{1}$, Adolfo Tiago Ferreira Lima ${ }^{3}$, Joseney Sprea ${ }^{1}$

${ }^{1}$ Faculdade Ranchariense - FRAN, Curso de Educação Física, Grupo UNIESP, Rancharia, SP. ${ }^{2}$ Universidade Estadual Paulista - UNESP, Programa de Pós Graduação em Educação, Presidente Prudente, SP. ${ }^{3}$ Universidade do Oeste Paulista - UNOESTE, Curso de Educação Física, Presidente Prudente, SP. E-mail: ander uai@hotmail.com

\section{RESUMO}

Esse trabalho objetiva destacar que o conteúdo televisivo deve ser considerado em debates, discussões e trabalhos na formação profissional dos licenciados em Educação Física. A televisão é um veículo de comunicação de massa que expande gradativamente sua produção, sendo considerada importante fonte de transmissão de informações para boa parte da população mundial diariamente. Dessa forma, algumas questões nortearam esse estudo, dado que consideramos que um momento propício e eficaz para desenvolver a educação do professor é durante a sua formação profissional: como os futuros professores de Educação Física percebem as influências da mídia televisiva em seu trabalho diário junto aos alunos e demais professores? Como desenvolver uma visão reflexiva acerca das práticas físicas que se espalharam pelos meios de comunicação? Para isso, foi realizada uma revisão de literatura que teve por base pesquisadores da área de Educação Física e/ou que discutem o referencial sociocultural. Durante a formação profissional em Educação Física os professores devem se preocupar com as influências da mídia e usá-la de forma reflexiva como suporte na educação, incluindo os meios de comunicação ao conteúdo pedagógico.

Palavras - chave: Formação Profissional. Mídia. Televisão.

\section{TELEVISION CONTENT IN TRAINING IN PHYSICAL EDUCATION}

\begin{abstract}
This work aims to highlight the television content should be considered in discussions and work in vocational training of graduates in Physical Education. Television is a mass communication vehicle that gradually expands its production and is considered an important source of transmission of information for much of the world's population daily. Thus, some questions guided this study, as we consider that a good time and effective for developing teacher education is during their vocational training: as future physical education teachers realize the influences of television media in their daily work with the students and other teachers? How to develop a reflective view on the physical practices that have spread by the media? For this, a literature review that was based on researchers in the field of Physical Education and/or discussing the sociocultural framework. During the vocational training in physical education teachers should be concerned about the influence of media and use it reflexively to support education, including the media to educational content.
\end{abstract}

Key Words: Vocational Training. Media. Television. 


\section{INTRODUÇÃO}

A televisão é um meio de comunicação de massa que desde a década de 1940 tem ampliado a produção e o consumo de informações junto à população mundial, sendo assim considerado um importante veículo de informação para o dia a dia.

O conteúdo televisivo pode provocar diferentes comportamentos nas pessoas, consideradas "telespectadores", que vão desde influências no pensar, no viver, na afetividade até aspectos mais amplos da vida, como o amar e o agir. Dessa forma, os professores de Educação Física podem colaborar para a orientação reflexiva da população acerca dos conteúdos transmitidos ${ }^{1}$. Um momento propício e eficaz para desenvolver a reflexão dos professores para essa temática é durante o seu processo de formação profissional, ou seja, nos cursos de graduação em Educação Física que frequentam antes de adentrar à sala de aula como profissionais ${ }^{1}$.

Diante desse panorama, é importante questionar como os futuros docentes de Educação Física compreendem os conteúdos televisivos sobre os elementos da cultura corporal? Como os cursos de Educação Física podem contribuir para que os sujeitos desenvolvam uma visão reflexiva em relação à difusão das práticas corporais pela mídia televisiva? De outra forma, a Educação Física tem como especificidade o estudo dos elementos da cultura corporal - danças, esportes, ginásticas, jogos e lutas ${ }^{2}$; sendo assim, a discussão nos cursos de formação profissional acerca dos significados que a mídia atribui a tais elementos poderá contribuir para que os discentes de Educação Física tenham um olhar reflexivo sobre a influência da mídia e desenvolvam uma atuação futura efetiva, considerando tais influências ${ }^{3}$.

Sendo assim, o presente estudo enfoca tais questionamentos e objetiva analisar os conteúdos televisivos como elementos a serem discutidos e considerados na formação profissional em Educação Física.

\section{METODOLOGIA}

Para tanto, foi desenvolvido um levantamento bibliográfico junto a autores que discutem a temática da Educação Física, caracterizado enquanto uma pesquisa de cunho qualitativo. Segundo Minayo ${ }^{4}$, a pesquisa qualitativa:

[...] responde a questões muito particulares. Ela se ocupa, nas Ciências Sociais, com um nível de realidade que não pode e não deve ser quantificado. Ou seja, ela trabalha com o universo dos significados, dos motivos, das aspirações, das crenças, dos valores e das atitudes. (p.21, 2007). 
Em concordância com a autora acreditamos ser a abordagem qualitativa a melhor maneira de se proceder ao longo do caminho no presente estudo, tendo o propósito de discutir e apresentar aos alunos (futuros professores de Educação Física) as construções simbólicas presentes nas programações televisivas intituladas como "lutas, ginásticas, jogos de futebol, vôlei ou danças" transmitidas diariamente.

\section{Entendendo a mídia como recurso pedagógico}

Segundo Castells ${ }^{1}$, por volta de 700 a. C. ocorreu o surgimento do alfabeto. Esse acontecimento serviu de base para o desenvolvimento da Filosofia e da Ciência Ocidental como as conhecemos hoje, pois, com o advento da sociedade moderna, as formas simbólicas tiveram um desenvolvimento rápido em função do capitalismo e de um significativo avanço nos meios técnicos. O desenvolvimento do alfabeto teve um importante papel nesse momento, por este ser entendido como uma forma simbólica com uma função fundamental na sociedade, ou seja, a produção e a troca das próprias formas simbólicas, que, segundo Thompson ${ }^{5}$, podem ser consideradas como expressões linguísticas, gestos, ações, obras de artes etc.

De acordo com Thompson ${ }^{5}$, foram desenvolvidos meios técnicos na sociedade moderna em conjunto com instituições orientadas para acumulação capitalista, possibilitando a produção e circulação de panfletos, jornais, revistas e livros, onde se produziu uma quantidade sempre crescente durante os séculos XVII, XVIII e XIX. Em meados do século XIX houve uma expansão significativa desses meios técnicos nos níveis de alfabetização e toda essa expansão ganha o nome de "comunicação de massa" - meios que receberam auxílio posterior com o progresso na transmissão e codificação de formas simbólicas ${ }^{5}$.

As formas simbólicas estão sempre inseridas em contextos sociais e são estruturadas de acordo com a sociedade, pois além de serem expressões de um sujeito, geralmente são produzidas por agentes situados dentro de um contexto sócio-histórico específico com vários recursos e várias capacidades ${ }^{6}$.

O modo como as formas simbólicas são compreendidas pelos sujeitos pode depender dos recursos e capacidades utilizados no processo de interpretação de cada um deles. Os sujeitos sempre compreenderão, de certa forma, as influências da mídia; a diferença é como poderão ter uma atitude ativa e reflexiva diante da mesma ou receber as informações passivamente, reproduzindo a ideologia dos meios de informação ${ }^{7}$.

Diante disso, concordamos com Pires $^{8}$ ao dizer que a sociedade precisa estar atenta às informações apresentadas pela mídia no dia-a-dia para não ser influenciada de maneira passiva 
durante suas programações e, principalmente, propagandas diárias. É preciso ter um olhar reflexivo no momento em que se busca uma informação, pois há a predominância da produção e difusão de imagens com conteúdos meramente voltados ao consumismo, à falta de problematização etc.

O conteúdo midiático transmitido pela televisão deveria fazer parte das discussões no ambiente escolar desde as turmas de Educação Infantil. Os sujeitos deveriam ser educados para aprender a lidar com a mídia no momento de receberem a sua mensagem, para, assim, poderem formular os seus conceitos. Na área da Educação Física pode utilizar-se o esporte como contribuição para os educadores, pois que a partir do esporte possam construir uma reflexão sobre a mídia junto aos alunos 9 .

O debate sobre o esporte, por exemplo, inserido na formação profissional, pode ser utilizado como auxílio pedagógico e, por meio deste, ensinar os alunos a praticar as modalidades esportivas e interpretá-las conforme apresentadas pela televisão ${ }^{10}$. O professor pode discutir e fornecer aos alunos subsídios para serem críticos e reflexivos diante de determinada modalidade esportiva, pois os esportes criam grandes "ídolos" e estes podem ser usados como marketing esportivo, como bem pode-se ver nas figuras mundialmente conhecidas do esporte: por intermédio da figura deste ídolo a mídia dita as tendências da moda esportiva, por exemplo.

A mídia televisiva também propõe uma nova visão sobre o evento esportivo (como também observa-se nas propagandas transmitidas), pois traz repetições das partes importantes e interessantes para seus idealizadores, apresenta lances e assuntos espetaculares, facilitando a comercialização e a divulgação do seu produto ${ }^{8}$.

Nesse sentido, é fundamental os estudantes de Educação Física terem acesso a conceitos teóricos sobre a mídia para assim compreenderem as informações e imagens difundidas por essa instituição e para que em sua atuação profissional futura possam considerar as influências da mídia na difusão das práticas corporais junto a seus alunos ${ }^{11}$. Os professores precisam desenvolver criticidade perante os programas televisivos e estes podem usar os modos de operação da ideologia.

Há cinco modos de operação da ideologia, que se subdividem em algumas estratégias típicas de construção simbólica, em que os professores podem encontrar subsídios para suas discussões sobre algumas formas para usarem televisão, jornais e revistas de maneira reflexiva e ativa ${ }^{5}$. Para o autor, "o estudo da ideologia serve para investigar as maneiras como o sentido das coisas são construídas e utilizadas pelas formas simbólicas de vários tipos, como linguagem cotidiana e até textos complexos" ${ }^{\prime 5}$. 


\section{RESULTADOS}

O docente em formação profissional em Educação Física precisa ficar atento, pois os alunos podem não estar preparados para lidar com o conteúdo midiático, tornando-se consumidores descontrolados de seus produtos. Sendo assim, por meio de discussões e debates estes podem aprender a interpretar os conteúdos televisivos vinculados pela mídia.

No entanto, cabe o questionamento como os estudantes de Educação Física, recebem e compreendem as formas simbólicas apresentadas pela televisão? Thompson $(2009)^{5}$ define cinco modos de operação da ideologia se dão independentemente uns dos outros. Esses podem sobrepor-se e reforçar-se mutuamente, podendo associar-se a certas estratégias de construção simbólica: existem certas estratégias tipicamente associadas com certos modos, embora reconheçam suas circunstâncias particulares, toda estratégia dada pode servir a outros propósitos e todo modo apresentado pode ser atualizado de outras maneiras.

Quadro 1. Modos de operação de ideologia, proposto por Thompson ${ }^{5}$.

\begin{tabular}{|l|l|}
\hline Modos Gerais & Algumas Estratégias Típicas de Construção Simbólica \\
\hline Legitimação & Racionalização, Universalização e Narrativização. \\
\hline Dissimulação & Deslocamento, Eufemização e Tropo (sinédoque, metonomia e metáfora). \\
\hline Unificação & Estandardização e Simbolização da Unidade. \\
\hline Fragmentação & Diferenciação e Expurgo do Outro. \\
\hline Reificação & Naturalização, Eternalização e Nominalização/Passivização. \\
\hline
\end{tabular}

\section{DISCUSSÃO}

Os cinco modos de operação da ideologia vão ao encontro dos objetivos propostos no presente estudo e podem ser explicitados da seguinte forma quando se pensa nos conteúdos televisivos transmitidos diariamente para a população:

1) Legitimação: a mídia constrói uma série de justificativas para defender aquilo que acredita ser uma ideia boa; subdivide-se em três estratégias Racionalização (desenvolvida numa linguagem simples e fácil, com alguns dados científicos); Universalização (estratégia usada para servir ao interesse de todos os telespectadores) e Narrativização (histórias que contam o passado e tratam o presente como parte de uma tradição aceitável. Muitas vezes a história é inventada a fim de criar um sentido de pertença a uma comunidade $)^{5}$.

2) Dissimulação: consiste em uma relação de sustentação e usa a imagem de pessoas com produtos para desviar a atenção do telespectador (por exemplo, utiliza a imagem do atleta com o 
produto que a mídia quer oferecer). Subdivide-se em três categorias: Deslocamento (fazer referência ao atleta, onde o mesmo é visto como herói); Eufemização (a descrição de instituições e relações sociais para despertar uma valoração positiva) e Tropo ${ }^{1}$ - valorização do uso figurativo da linguagem ou das formas simbólicas, apresentadas em três formas mais comuns - sinédoque, metonímia e metáfora ${ }^{5}$.

3) Unificação: construção simbólica e tem o sentido de uma constituição científica, interligando os indivíduos numa identidade coletiva, independente das diferenças e divisões que possam separá-los. Uma estratégia típica por meio do qual o modo é expresso em formas simbólicas é a estratégia da padronização. As formas simbólicas são adaptadas a um referencial padrão proposto como fundamento partilhado e aceitável, por exemplo, linguagem nacional pode servir para criar uma identidade coletiva entre grupos e uma hierarquia legitimada entre línguas e dialetos dentro dos limites de um estado e nação. A Simbolização da unidade é uma estratégia para envolver a construção de símbolos de unidade, de identidade e de identificação coletiva ou de uma pluralidade de grupos, por exemplo, a Copa do Mundo: a cidade toda se enfeita de verde e amarelo ${ }^{5}$.

4) Fragmentação: estabelece relação de dominação e pode manter as pessoas em coletividade, mas segmenta aqueles indivíduos e grupos que possam ser capazes de se transformar num desafio real aos grupos dominantes ou dirigidos por forças de oposição, subdividindo-se enquanto diferenciação; são características para edificar a imagem negativa do outro ${ }^{5}$.

5) Reificação: são relações de dominação e subdividem-se em três categorias: Naturalização (a criação social e histórica pode ser tratada como um acontecimento quase natural), Eternalização (são fenômenos sócio históricos esvaziados de seu caráter histórico, a serem apresentados como permanentes, imutáveis e recorrentes. Pode-se citar como exemplo costumes, tradições e instituições que parecem prolongar-se indefinidamente em direção ao passado, de tal forma que todo traço sobre sua origem fica perdida e todo questionamento sobre sua finalidade é inimaginável, adquirindo, então, uma rigidez que não pode ser facilmente quebrada) e Nominalização/passivização (a nominalização acontece quando a descrição da ação e dos participantes nelas envolvidos é transformada em nomes, por exemplo, no futebol; "atleta do Esporte Clube Estrela foi suspenso por excesso de álcool" ao invés de "Máx atacante do Estrela Esporte Clube foi suspenso por uso excessivo de álcool". A passivização se dá quando o verbo é apresentado na voz passiva, quando diz: "O atleta do Porto Roque está sendo investigado pela

\footnotetext{
${ }^{1}$ Qualquer figura em que se empregam palavras com um sentido diferente do habitual: a metonímia e a metáfora são tropos. 
Confederação de Futebol", ao invés de dizer "a Confederação de Futebol está investigando o atleta do Porto Roque Esporte Clube"). A nominalização e a passivização concentram a atenção do ouvinte em certos assuntos e prejudicam outros; elas apagam os atores e as ações principais da notícia, representando-os como coisas ou acontecimentos ${ }^{5}$.

O professor do ensino superior pode utilizar esses modos de operação da ideologia nas aulas de Educação Física para os alunos entenderem as transmissões oferecidas pelos meios de comunicação de massa, especificamente os conteúdos televisivos. Dessa maneira, podem analisar os elementos da cultura corporal e interpretarem os significados da mídia de forma mais consciente, reflexiva e ativa $^{8}$. Dessa forma, é possível compreender melhor como se dá a construção de informações por parte da mídia.

\section{CONCLUSÃO}

Este estudo tem o intuito de contribuir, de modo singelo, com os futuros professores para que eles analisem a mídia de maneira crítica e reflexiva, pois os elementos da cultura corporal, como "lutas, esportes, danças, jogos e ginástica", são elementos básicos da Educação Física e se estes conteúdos forem utilizados por meio dos modos de operação da ideologia, no momento da transmissão televisiva, os futuros professores podem aprender a fazer uma leitura da mídia televisiva de forma mais crítica, de modo a contribuir para o aprendizado. Percebe-se no processo de formação que o curso de Educação Física precisa se preocupar com as influências da mídia e utilizá-las como auxílio na educação, incluindo a mídia como estratégia pedagógica.

\section{REFERÊNCIAS}

1. CASTELLS, M. A sociedade em rede. 1ạ ed. Lisboa: Fundação Calouste Gulbenkian, 2002.

2. DAOLIO, J. Cultura: educação física e futebol. 3a ed. Campinas: Editora Unicamp, 2006.

3. BETTI, M. A janela de vidro: esporte, televisão e educação física. 1ạ ed - Campinas: Papirus, 1998.

4. MINAYO, C.S. (Org.). Pesquisa Social: teoria, método e criatividade. 25a ed. Petrópolis: Vozes, 2007.

5. THOMPSON, J. B. Ideologia e cultura moderna: teoria social crítica na era dos meios de comunicação de massa. 5 a ed. Petrópolis: Vozes, 2009.

6. THOMPSON, J. B. A mídia e a modernidade: uma teoria social da mídia. 12 a ed. Petrópolis: Vozes, 2011. 
7. TEDESCO, J. C. O novo pacto educativo: educação, competitividade e cidadania na sociedade moderna, 1a ed. São Paulo: Ática, 1995.

8. PIRES, L.G. Educação Física e o discurso midiático: abordagem crítico-emancipatória, 1a ed. ljuí: Editora Unijuí, 2002.

9. BETTI, M. Esporte, entretenimento e mídias: implicações para uma política de esporte e lazer. Piracicaba: Rev.Impulso, p. 83-89,2005.

10. NETO, A. F. (Org.) A virtualização do esporte e suas novas vivências eletrônicas. Educação Física e mídia: novos olhares, outras práticas. $1^{\text {a }}$ ed. São Paulo: Hucitec, 2003.

11. CARVALHO, A. S. Análise dos conteúdos virtuais relativos a vídeos sobre a cultura corporal e Educação Física. 2013. 103 f. Dissertação (Mestrado em Educação Física) - Universidade Metodista de Piracicaba - UNIMEP. Piracicaba, 2013. 